\title{
Neonatal non-laparoscopic non-robotic pneumovesical distension presenting as acute abdomen
}

\author{
Ramnik V Patel, ${ }^{1,2}$ Dhaval Govani, ${ }^{3}$ Rasila Patel, ${ }^{4}$ Pradip J Kansagra ${ }^{5}$
}

${ }^{1}$ Department of Paediatric Urology, University College London Hospitals NHS Foundation Trust, London, UK ${ }^{2}$ Department of Paediatric Urology, Great Ormond Street Children's Hospital NHS Trust, London, UK

${ }^{3}$ University of Birmingham Medical School, Birmingham, UK

${ }^{4}$ Department of Alternative Medicine, PGICHR, Rajkot, India

${ }^{5}$ Department of Paediatric Urology, PGICHR and Om Urology Hospital, Rajkot, Gujarat, India

\section{Correspondence to}

Ramnik V Patel,

ramnik@doctors.org.uk

Accepted 9 March 2014

\section{DESCRIPTION}

A term baby girl diagnosed prenatally with complex congenital heart disease was being investigated in the cardiac intensive care unit (ICU). The baby was stable on nasal oxygen and having full nasogastric feeds. Her urinary catheter was blocked despite the administration of $60 \mathrm{~mL}$ saline for irrigation and $60 \mathrm{~mL}$ of air via a bladder syringe by an evening duty nurse with urology experience. A Foley balloon inflated with saline failed to deflate, so the nurse injected $60 \mathrm{~mL}$ of air with a syringe through the balloon catheter channel in order to rupture the balloon. This was not documented in the notes. That night the baby's oxygen saturation decreased, she developed abdominal distension and an increase in lactate levels was noted. Chest and abdominal radiographs showed a large gas shadow in the central abdomen without any air under the domes of the diaphragm or any evidence of necrotising enterocolitis (figure 1A, B). The patient was referred to the surgical team for possible contained bowel perforation. The abdomen was distended but soft and bowel sounds were normal. At exploration, there was no free gas or fluid, but the bladder was seen to be inflated with air. Needle aspiration confirmed this and was used to decompress the distended bladder. Cystourethroscopy showed several small remnants of a Foley catheter balloon which were removed. The post-operative period was uneventful (figure 1C, D).

Pneumodistension of the bladder is used in laparoscopic and robotic bladder surgery, but otherwise very small amounts of air are present in the bladder, even in pathological states. ${ }^{1}$ Foley catheter lumen blockade and simultaneous blockade of the non-return valve channel is rare and requires 


\section{Learning points}

- The normal capacity of a neonatal bladder is $30 \mathrm{~mL}$, so the injection of $60 \mathrm{~mL}$ volume each of saline and air to unblock a catheter lumen followed by another $60 \mathrm{~mL}$ of air for a total volume of $180 \mathrm{~mL}$ caused acute pneumodistension in this patient.

- To prevent rare blockage by sodium chloride crystals of the lumen and non-return inflation valve in a Foley catheter, the balloon should be inflated with sterile water rather than normal saline.

- If deflating the balloon with an empty syringe presents a problem, normal procedures should be employed or those described in the specialist literature should be followed by a suitably qualified, trained and experienced neonatal and paediatric urologist.

- Foley balloons must never be inflated above the stated volume in order to rupture them as this can cause further complications.

- If a Foley balloon is ruptured, all larger fragments not passed in the urine must be carefully removed from the bladder as they may act as nidus for urosepsis and urolithiasis requiring surgery for bladder stone removal.

expert attention. ${ }^{2} 3$ The most common neonatal and paediatric urology emergency in ICUs is posterior urethral injury caused by inflation of the balloon during insertion of a Foley catheter, typically in a male baby, leading to partial urethral rupture and catastrophic sequelae. We wish to emphasise the importance of protocols, and the education and training of ICU staff in the insertion, maintenance and removal of Foley catheters even if they have previous exposure to urology nursing. If the nurse in this case had realised the normal size of a neonatal bladder, he/ she would never have injected as much air/fluid as was seen in this patient. Staff education, training and the implementation of a practical protocol are important for preventing such avoidable mistake in ICUs. This case serves as a very strong reminder of this rare complication and hopefully our experience will help prevent this error occurring again.

\begin{abstract}
Acknowledgements We are grateful to Dr Shudhir Bhimani, MD, Consultant Paediatric Cardiologist, Dr S Vaghela, MS, MCh, FRCS, Consultant Paediatric Cardiothoracic Surgeon, Dr GM Faldu, MD, Consultant Paediatric Anaesthetist, and Dr Nayan Kalawadia, MD and Dr Anil Patel, MD, DCH, Consultant Neonatal Intensivists for their expert help and assistance in this case.
\end{abstract}

Contributors All the authors made substantial contributions to the conception and design of this paper, the literature search, the acquisition, analysis and interpretation of data, and drafting the article or revising it critically for important intellectual content, and gave final approval of the version to be published.

Competing interests None.

Patient consent Obtained.

Provenance and peer review Not commissioned; externally peer reviewed.

\section{REFERENCES}

1 Joseph RC, Amendola MA, Artze ME, et al. Genitourinary tract gas: imaging evaluation. Radiographics 1996;16:295-308.

2 Daneshmand S, Youssefzadeh D, Skinner EC. Review of techniques to remove a Foley catheter when the balloon does not deflate. Urology 2002;59:127-9.

3 Patterson R, Little B, Tolan J, et al. How to manage a urinary catheter balloon that will not deflate. Int Urol Nephrol 2006;38:57-61.

Copyright 2014 BMJ Publishing Group. All rights reserved. For permission to reuse any of this content visit http://group.bmj.com/group/rights-licensing/permissions.

BMJ Case Report Fellows may re-use this article for personal use and teaching without any further permission.

Become a Fellow of BMJ Case Reports today and you can:

- Submit as many cases as you like

- Enjoy fast sympathetic peer review and rapid publication of accepted articles

- Access all the published articles

- Re-use any of the published material for personal use and teaching without further permission

For information on Institutional Fellowships contact consortiasales@bmjgroup.com

Visit casereports.bmj.com for more articles like this and to become a Fellow 